\title{
EXPLORING THE IMPACT OF THE COMPLEXITY OF COGNITIVE DEMANDS ASSOCIATED WITH CURRICULUM CONTENT ON STUDENT ACADEMIC PERFORMANCE: A CASE OF MATHEMATICS
}

\author{
Sam Ramaila ${ }^{1}$, Philemon Seloane ${ }^{2}$, \& Lydia Mavuru ${ }^{1}$ \\ ${ }^{1}$ Department of Science and Technology Education, University of Johannesburg (South Africa) \\ ${ }^{2}$ Department of Pure and Applied Mathematics, University of Johannesburg (South Africa)
}

\begin{abstract}
Student academic performance is intrinsically linked to the complexity of the cognitive demands associated with curriculum content on offer. Skills development is largely regarded as a fundamental process that serves to engender critical expertise required for economic growth and sustainable development. The ability to operate at various cognitive levels is central to meaningful enhancement of human capital development. Meaningful development of mathematical skills in particular hinges to a large degree on the extent to which students are able to grasp curriculum content associated with various learning areas. The development of adequate cognitive competence to grapple with mathematics curriculum content would certainly make it possible for students to perform routine operations as well as complex procedures associated with various mathematical tasks. In response to this key imperative, the impact of cognitive demands associated with curriculum content on student academic performance was explored by tracking the academic performance of undergraduate engineering students in mathematics at a South African university over two semesters as part of a longitudinal study. This cohort of students was purposively selected as mathematics is largely viewed as an intellectually stimulating discipline providing opportunities for students to indulge in tasks pitched at various cognitive levels. The study revealed that student academic performance based on mathematics curriculum content offered in the second semester was inadequate. This inadequate academic performance can partly be attributed to the students' inability to cope with the complexity of the cognitive demands associated with mathematics curriculum content offered in the second semester. Theoretical implications for meaningful critical reflection on the complexity of cognitive demands associated with curriculum content are discussed.
\end{abstract}

Keywords: Cognitive demands, mathematical skills, cognitive levels.

\section{Introduction}

The ability to operate at various cognitive levels is central to meaningful enhancement of human capital development. Meaningful development of mathematical skills in particular hinges to a large degree on the extent to which students are able to grasp curriculum content associated with various learning areas. Bloom (1956) devised a model for classifying thinking into six cognitive levels of complexity. The cognitive levels in order of increasing complexity are: knowledge, comprehension, application, analysis, synthesis, and evaluation. However, the original Bloom's Taxonomy was revised by Anderson and Krathwohl (2001) and this revision culminated in a transformation of the six cognitive levels to indicate action verbs. The revised model by Anderson and Krathwohl (2001) generated the following six cognitive levels: remembering, understanding, applying, analysing, evaluating, and creating. In view of the fundamental revision of Bloom's Taxonomy, the mathematics education community called for a reform in the knowledge and skills required for enactment of effective teaching practice (Heck, Banilower, Weiss, \& Rosenberg, 2008).

The meaning of cognitive demand has been subjected to various scholarly interpretations. According to Stein, Smith, Henningsen and Silver (2009), the cognitive demand is the variation in the kind of thinking required of students engaging in a mathematical task. They identified the four levels characterising cognitive demand, namely: (a) memorization; (b) procedures without connections; (c) procedures with connections; and (d) doing mathematics. More specifically, the level of cognitive demand determines the depth of understanding acquired by students in the learn process (Stein, Smith, Henningsen, \& Silver, 2009). On the other hand, Park (2011: 5) defines cognitive demand as the 'amount 
of intellectual activity required to perform a task'. The cognitive demand is further viewed by Henningsen and Stein (1997: 529) as the 'kind of thinking processes entailed in solving the tasks'. It is against this background that this research study primarily explored the impact of the complexity of cognitive demands associated with curriculum content on student academic performance in mathematics as a key knowledge domain.

\section{Research design and methodology}

This study adopted a cohort design as it involved participants who are united by some commonality or similarity (Healy \& Devane, 2011). The cohort consisted of undergraduate students who were enrolled for a degree program in Metallurgical Engineering. This cohort constituted a purposive sample within the context of this study. The student academic performance in mathematics was tracked over two semesters with a view to assess the complexity of the cognitive demands associated with the mathematics curriculum content covered.

\section{Results and discussion}

Table 1 below provides mathematics curriculum content covered in the first semester and second semester.

Table 1. Mathematics curriculum content covered in the first semester and second semester.

\begin{tabular}{|l|l|}
\hline $\begin{array}{l}\text { Mathematics curriculum content covered in the } \\
\text { first semester }\end{array}$ & $\begin{array}{l}\text { Mathematics curriculum content covered in } \\
\text { the second semester }\end{array}$ \\
\hline Functions and relation & The meaning of complex numbers \\
Algebraic graphs & Algebraic operations with complex numbers \\
The binomial & Differentiation \\
Determinants & Limits of functions \\
Transcendental functions & Rates of change \\
Exponents and the exponential function & Rules for differentiation \\
Logarithms & Derivatives of transcendental functions \\
Graphs of the exponential and logarithmic & Higher derivatives \\
functions & Applications of differentiation \\
Formulae & Integration \\
Trigonometric function & \\
\hline
\end{tabular}

The academic performance in the first and second semester is depicted in Figure 1 below. The academic performance in the second semester was dismal (24\%) as compared to the first semester (80\%). This performance disparity can partly be attributed to the comparative complexity of the cognitive demands associated with the mathematics curriculum content covered during the two semesters. The academic performance demonstrated by the students in the first semester can be attributed to the strong connection between the mathematics curriculum content covered in the first semester and school mathematics curriculum content. Battista (1994) argues that students are not achieving their fullest potential in mathematics for various reasons, but it is clear that improvement in the quality of mathematics teaching needs to occur in order to combat low student achievement. Other researchers such as Karp et al. (2011) are of the view that some students are not given ample opportunities to learn important mathematics while other students are not challenged by the curriculum, and yet other students do not actively engage in the mathematics. This has profound implications for the design of the mathematics learning tasks students engage in. Mathematics learning tasks in which students engage ought to provide rich pedagogic benefits and experiences for students to realise their key learning outcomes. The development of adequate cognitive competence to grapple with mathematics curriculum content would certainly make it possible for students to perform routine operations as well as complex procedures associated with various mathematical tasks. As noted by Resnick (2006), the mathematical tasks in which students engage serve to convey a message about the nature of mathematics and influence students' understanding of concepts and processes. Implementing tasks of high cognitive demand can be an arduous process in itself as problems of high cognitive demand are more ambiguous and have multiple solution paths (Henningsen, \& Stein, 1997). 
Figure 1. Academic performance in the first and second semester.

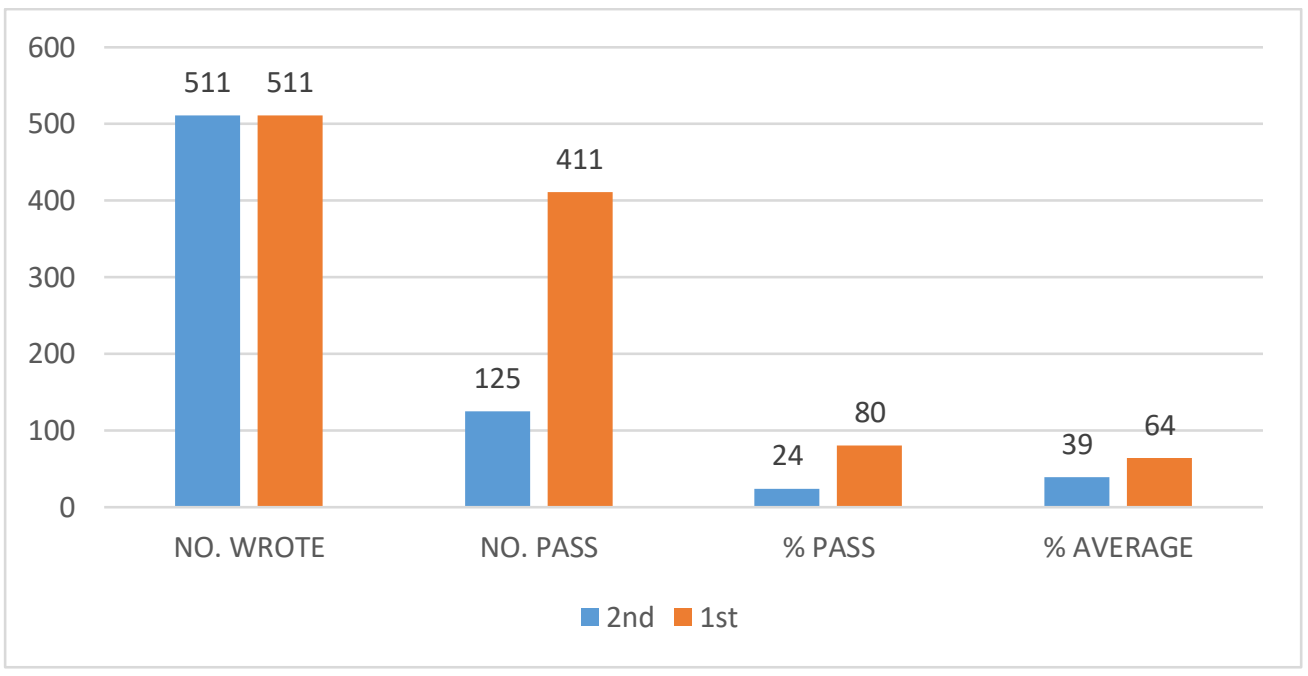

Figure 2 below depicts academic performance across the various percentage bands in the first semester. The performance of a substantial number of students (54\%) fell within the $50 \%-74 \%$ band.

Figure 2. Performance across various percentage bands: First Semester.

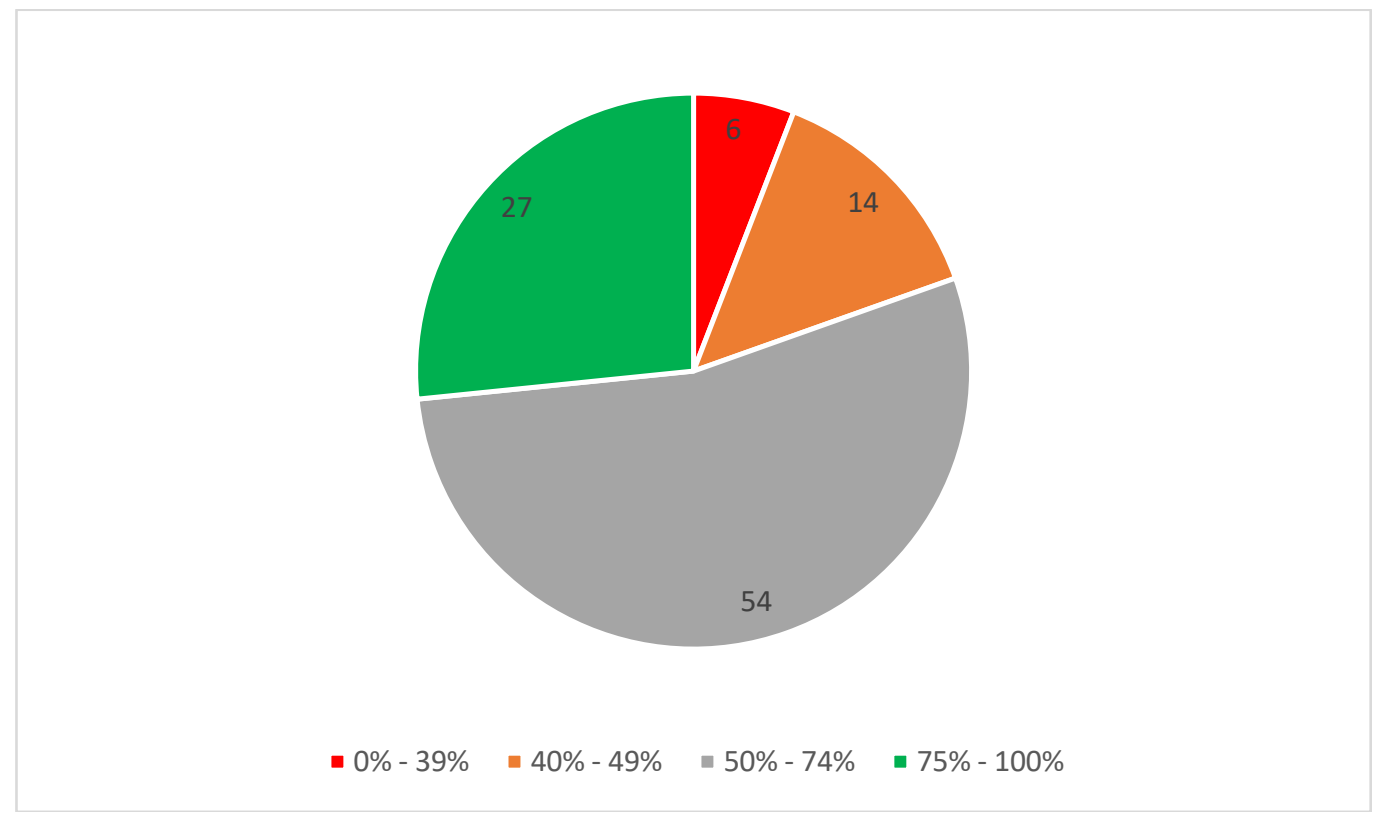

The academic performance across the various percentage bands in the second semester reflects a gloomy picture as the performance of most students fell within the 0\%-39\% band. This predicament calls for creative ways through which mathematics curriculum content can taught in an intellectually accessible manner. This key goal can accomplished by selecting tasks that promote deep engagement and meaningful discussion in the classroom (Smith, Bill, \& Hughes, 2008; Stein, Smith, Henningsen, \& Silver, 2009). In addition, student understanding can be enhanced through the lens of a particular learning trajectory which essentially helps instructors to visualize a continuum of student understanding and how to help the students increase or deepen understanding (Clements \& Sarama, 2009; Sarama \& Clements, 2009). 
Figure 3. Performance across various percentage bands: Second Semester.

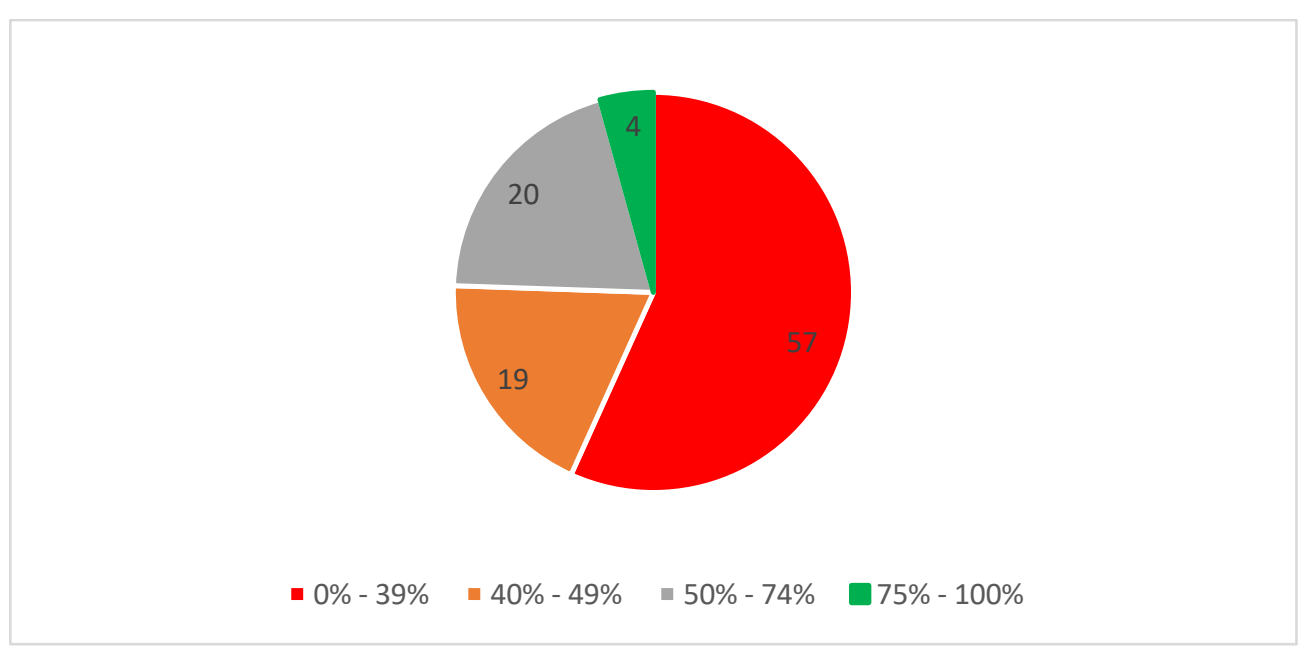

\section{Conclusions}

The complexity of the impact of cognitive demands associated with mathematics curriculum content in particular requires constant interrogation in order to provide meaningful learning opportunities to students. Student under-preparedness is a pervasive problem afflicting meaningful development of mathematical skills within the broader South African context and concerted efforts in this regard would serve to enhance throughput which is intrinsically linked to quality and improved student academic performance. The ability to operate at various cognitive levels is central to meaningful enhancement of human capital development and this key strategic imperative requires instructors to demystify the complexity of the impact of cognitive demands associated with curriculum content.

\section{References}

Anderson, L.W. \& Krathwohl, D.R. (Eds.) (2001). A Taxonomy for Learning, Teaching, and Assessing: A revision of Bloom's Taxonomy of Educational Objectives: Complete Edition. New York: Longman.

Battista, M. T. (1994). Teacher beliefs and the reform movement in mathematics education. The Phi Delta Kappan, 75(6), 462-470.

Bloom, B.S. (1956). Taxonomy of Educational Objectives, Handbook 1: Cognitive Domain. New York: Longman.

Clements, D. H., \& Sarama, J. (2009). Learning and teaching early math: The learning trajectories approach. New York: Routledge.

Healy, P \& Devane D. (2011). Methodological considerations in cohort study designs. Nurse Researcher, 18, 32-36.

Heck, D. J., Banilower, E. R., Weiss, I. R., \& Rosenberg, S. L. (2008). Studying the effects of professional development: The case of the NSF's local systematic change through teacher enhancement initiative. Journal for Research in Mathematics Education, 39(2), 113-152.

Henningsen, M., \& Stein, M. K. (1997). Mathematical tasks and student cognition: Classroom-based factors that support and inhibit high-level mathematical thinking and reasoning. Journal for Research in Mathematical Education, 28(5), 524-549.

Karp, K., Caldwell, J., Zbiek, R. M., Bay-Williams, J. (2011). Developing essential understandings of addition and subtraction for teaching mathematics in pre-k-grade 2. Reston, VA: National Council of Teachers of Mathematics.

Park, A.M. (2011). Comparing the Cognitive Demand of Traditional and Reform Algebra 1 Textbooks.

Sarama, J., \& Clements, D. H. (2009). Early childhood mathematics education research: Learning trajectories for young children. New York: Routledge.

Smith, M. S., Bill, V., \& Hughes, E. K. (2008). Thinking through a lesson: Successfully implementing high-level tasks. Teaching Mathematics in the Middle School, 14(3), 132-138.

Stein, M. K., Smith, M. S., Henningsen, M. A., \& Silver, E. A. (2009). Implementing standards-based mathematics instruction, a casebook for professional development. New York: Teachers College Press, Reston, VA: National Council of Teachers of Mathematics. 